NASA/TM-2003-212535

High Frequency Adaptive Instability Suppression Controls in a Liquid-Fueled Combustor

George Kopasakis

Glenn Research Center, Cleveland, Ohio 
Since its founding, NASA has been dedicated to the advancement of aeronautics and space science. The NASA Scientific and Technical Information (STI) Program Office plays a key part in helping NASA maintain this important role.

The NASA STI Program Office is operated by Langley Research Center, the Lead Center for NASA's scientific and technical information. The NASA STI Program Office provides access to the NASA STI Database, the largest collection of aeronautical and space science STI in the world. The Program Office is also NASA's institutional mechanism for disseminating the results of its research and development activities. These results are published by NASA in the NASA STI Report Series, which includes the following report types:

- $\quad$ TECHNICAL PUBLICATION. Reports of completed research or a major significant phase of research that present the results of NASA programs and include extensive data or theoretical analysis. Includes compilations of significant scientific and technical data and information deemed to be of continuing reference value. NASA's counterpart of peerreviewed formal professional papers but has less stringent limitations on manuscript length and extent of graphic presentations.

- TECHNICAL MEMORANDUM. Scientific and technical findings that are preliminary or of specialized interest, e.g., quick release reports, working papers, and bibliographies that contain minimal annotation. Does not contain extensive analysis.

- CONTRACTOR REPORT. Scientific and technical findings by NASA-sponsored contractors and grantees.
- CONFERENCE PUBLICATION. Collected papers from scientific and technical conferences, symposia, seminars, or other meetings sponsored or cosponsored by NASA.

- SPECIAL PUBLICATION. Scientific, technical, or historical information from NASA programs, projects, and missions, often concerned with subjects having substantial public interest.

- TECHNICAL TRANSLATION. Englishlanguage translations of foreign scientific and technical material pertinent to NASA's mission.

Specialized services that complement the STI Program Office's diverse offerings include creating custom thesauri, building customized databases, organizing and publishing research results ... even providing videos.

For more information about the NASA STI Program Office, see the following:

- Access the NASA STI Program Home Page at http://www.sti.nasa.gov

- E-mail your question via the Internet to help@sti.nasa.gov

- Fax your question to the NASA Access Help Desk at 301-621-0134

- Telephone the NASA Access Help Desk at 301-621-0390

- Write to:

NASA Access Help Desk

NASA Center for AeroSpace Information 7121 Standard Drive

Hanover, MD 21076 
NASA/TM-2003-212535

\section{High Frequency Adaptive Instability Suppression Controls in a Liquid-Fueled Combustor}

George Kopasakis

Glenn Research Center, Cleveland, Ohio

Prepared for the

39th Joint Propulsion Conference and Exhibit cosponsored by AIAA, ASME, SAE, and ASEE Huntsville, Alabama, July 20-23, 2003

National Aeronautics and

Space Administration

Glenn Research Center 
The Propulsion and Power Program at NASA Glenn Research Center sponsored this work.

Available from

NASA Center for Aerospace Information 7121 Standard Drive

Hanover, MD 21076
National Technical Information Service 5285 Port Royal Road Springfield, VA 22100

Available electronically at http:/ /gltrs.grc.nasa.gov 


\title{
HIGH FREQUENCY ADAPTIVE INSTABILITY SUPPRESSION CONTROLS IN A LIQUID-FUELED COMBUSTOR
}

\author{
George Kopasakis* \\ National Aeronautics and Space Administration \\ Glenn Research Center \\ Cleveland, Ohio 44135
}

\begin{abstract}
This effort extends into high frequency $(>500 \mathrm{~Hz})$, an earlier developed adaptive control algorithm for the suppression of thermo-acoustic instabilities in a liquidfueled combustor. The earlier work covered the development of a controls algorithm for the suppression of a low frequency $(\sim 280 \mathrm{~Hz})$ combustion instability based on simulations, with no hardware testing involved. The work described here includes changes to the simulation and controller design necessary to control the high frequency instability, augmentations to the control algorithm to improve its performance, and finally hardware testing and results with an experimental combustor rig developed for the high frequency case. The Adaptive Sliding Phasor Averaged Control (ASPAC) algorithm modulates the fuel flow in the combustor with a control phase that continuously slides back and forth within the phase region that reduces the amplitude of the instability. The results demonstrate the power of the method - that it can identify and suppress the instability even when the instability amplitude is buried in the noise of the combustor pressure. The successful testing of the ASPAC approach helped complete an important NASA milestone to demonstrate advanced technologies for low-emission combustors.
\end{abstract}

\section{INTRODUCTION}

Lean-burning, low emission combustors are being investigated for aircraft gas turbine engines. Lean combustion is shown to be advantageous for NOx emissions and efficiency, but suffers from an increased susceptibility to thermo-acoustic instabilities. These instabilities typically result from coupling of the fluctuating heat release ${ }^{1}$ or coupling of the equivalence ratio modulation of the combustion process with the lightly damped acoustics of the combustion chamber.
These instabilities cause pressure oscillations within the combustor that can reduce component life and potentially lead to premature mechanical failures

In recent years, suppression of thermo-acoustic instability has been attempted through active control. ${ }^{2}$ The goal of these active control efforts is to reduce the energy concentrated at the instability frequency and to reduce the overall amplitude of the combustor pressure oscillations. Some active control concepts involved speaker actuation or placing another heating source. ${ }^{3,4,5,6,7,8,9}$ Speaker actuation simplifies the problem by eliminating the need for fuel modulation control with all its adverse process characteristics. However, acoustic actuation may not be directly applicable to aircraft-type engines due to the harsh environment and weight restrictions. Others have attempted to actuate the fuel modulation with some limited success. ${ }^{10,11,12,13,14,15}$ These later control investigations have demonstrated some ability to reduce the frequency spectra of the instability but have been less successful at reducing the time domain pressure fluctuations.

Many of these active combustion control (ACC) techniques rely on accurate knowledge of the plant dynamics. However, the combustion process is rather complicated and difficult to model. The combustion process characteristics include large dead-time phase shifts, large wideband noise compared to the amplitude of the instability, exponential growth of the instability, frequency and phase shift randomness, ${ }^{16}$ and a system that transitions through inherently unstable operation. Because of these adverse process characteristics, the instability may grow very fast to unacceptable levels when even momentary loss of control tracking occurs. This momentary loss of control is inevitable when the instability has been suppressed down to the noise level.

"Member AIAA. 
This successful demonstration of ACC for the HF case was carried out with two distinct controllers developed by NASA. The second controller was observer based, called Multi-Scale Extended Kalman (MSEK) by $\mathrm{Le}^{17}$. Both controllers yielded good results. A summary of the whole NASA ACC effort and testing of the two controllers is reported by DeLaat. ${ }^{18}$

In the effort described in this paper, an adaptive phase shifting controller, ${ }^{19}$ previously developed for suppression of a simulated Low-Frequency (LF) $275 \mathrm{~Hz}$ instability in a liquid-fueled single nozzle combustor, will be extended for applications in the High Frequency (HF) $>500 \mathrm{~Hz}$ combustion instability regime. The control algorithm senses pressure fluctuations due to the instability, filters, and phase shifts these pressure fluctuations to actuate the fuel modulation in order to generate combustion pressure or heat release oscillations that are opposing to the chamber acoustics. The control is based on adaptive phase shifting, where the phase of the control vector continuously bounces from one boundary of an effective stability region (i.e. a phase region that favors instability suppression) to the other, in a back and forth sliding motion. The Adaptive Sliding Phasor Averaged Control (ASPAC) algorithm requires very little detailed knowledge of the plant dynamics. Since this methodology is not model based, it can be expected that this controller can perform well at different operating conditions or at deteriorating engine conditions, where the structure of the engine dynamics can vary.

The ASPAC controller is demonstrated on a liquidfueled single-nozzle combustor rig. Previous work involving the development of the ASPAC approach will be extended here from the LF simulated configuration to the HF simulation and to control testing on the actual combustor rig. This paper documents changes made to the LF configuration in order to convert it to a HF simulation with corresponding control design changes, as well as augmentation of the controller to improve its performance and adaptability. The paper is organized as follows. A description of the combustor rig is given, followed by a description of the plant reduced-order model used for the HF control development. Changes or improvements to the control method required for control of the HF instability are then described. Some brief results of the simulation studies using the ASPAC method are presented. Combustor testing is discussed and results that demonstrate the effectiveness of the control method are presented.

\section{COMBUSTION INSTABILITY RIG}

In order to focus control development toward realistic combustion instabilities, a combustor rig which

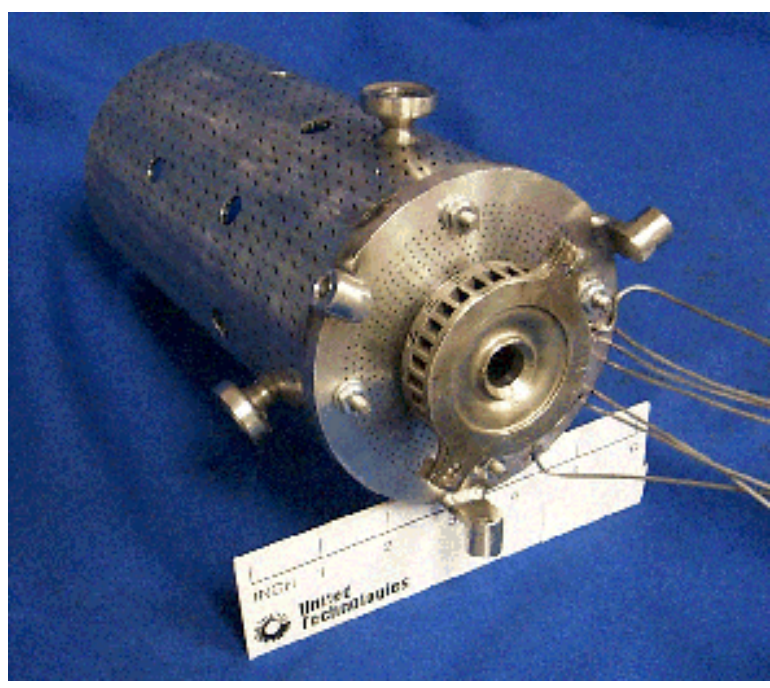

\section{Figure 1 - Combustor Rig for Combustor Instability Control Research}

\section{(Photo by United Technologies Research Center)}

replicates an engine combustion instability has been developed. ${ }^{20,21}$ The magnitude of the pressure oscillations in the engine was sufficient to cause unacceptable vibratory stresses in the turbine.

The rig successfully replicates the engine instability and operates at engine pressure and temperature conditions. The single-nozzle combustor rig has many of the complexities of a real engine combustor including an actual engine fuel nozzle and swirler, dilution cooling, and an effusion-cooled liner (Figure 1). For the conditions corresponding to the mid-power condition chosen for evaluation $\left(\mathrm{T} 3=770^{\circ} \mathrm{F}, \mathrm{P} 3=200 \mathrm{psia}\right.$, fuel-air ratio $=0.03$ ), test results established the existence of a combustion instability at approximately $566 \mathrm{~Hz}$.

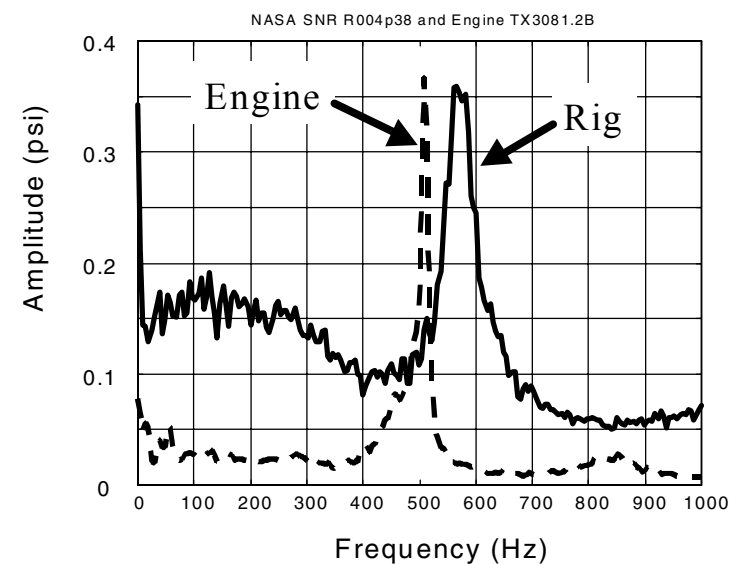

Figure 2 - Comparison of Engine and Baseline Combustor Rig Pressure Spectra 
A comparison between the pressure spectrum in the engine and in the single-nozzle combustor rig at comparable operating conditions is shown in Figure 2. As can be seen, the combustor rig approximates the engine instability frequency and amplitude. The combustor rig exhibits significantly higher wide band noise compared to the engine. As will be discussed later the noise level is the primary limiting factor of how much instability suppression can be achieved with a given control design. The level of noise in the rig makes it harder to extract the instability from among the noise and creates an additional challenge for the controller. The rig none-the-less provides a suitable, realistic test environment for combustion instability control research.

The research combustor rig was developed in partnership with Pratt \& Whitney and United Technologies Research Center (UTRC). Experimental testing with the combustor rig is taking place at UTRC.

\section{COMBUSTION INSTABILITY SIMULATION}

In a previous effort, a simulation for a $\mathrm{LF}(\sim 275 \mathrm{~Hz})$ instability, observed with a different rig configuration, was developed and simulations and control development were carried out. ${ }^{19}$ Because the instability frequency of the HF rig configuration is more engine like, the decision was made to adjust the controller design in order to attempt control of the HF instability. The basic ASPAC control/simulation structure remains unchanged for control of the HF instability, (Figure 3). Shown is the self-sustained oscillations loop $\left(G_{F}, G_{A}, N L\right)$ and the controller with the fuel valve actuation. In this closed loop simulation the overall combustor pressure is expressed as the sum of the instability pressure generated by the self-excited flame and acoustics loop, and the pressure caused by the controller actuated fuel modulation. There are many variations in previous published works as to how the physics of this control problem are interpreted and simulated. However, this controlled process boils down to a vector summation, vector rotation problem. ${ }^{19}$

The gain and damping for the reduced-order model of the LF and the HF combustor simulations remain the same. The frequencies were changed to simulate the HF instability. Based on this change, the new flame dynamics and acoustics models are as follows:

$$
\begin{gathered}
G_{F}=\frac{4500}{s+3770} \\
G_{A}=\frac{-3.26 e 6}{s^{2}+510.84 s+1.305 e 7}
\end{gathered}
$$

Based on these choices for $G_{F}$ and $G_{A}$ the instability is self-excited, that is, it requires no input other than nonzero initial conditions (via fuel injection modulation). The $G_{A}$ transfer function dynamics correspond to an instability frequency of $575 \mathrm{~Hz}$ with low damping ( $\varsigma=0.0707$ ). The instability loop response time is $\sim 0.6$ sec based on instability response measurements. ${ }^{2}$ The sampling time of $10 \mathrm{kHz}$ was selected to reflect the sampling frequency of the test hardware, which defines the controlled phase resolution. Given the choices of damping and sampling time this simulation is numerically unstable (limited by the saturation nonlinearity $N L$ ), which means the open-loop response also depends on the sampling time. Numerical instability is

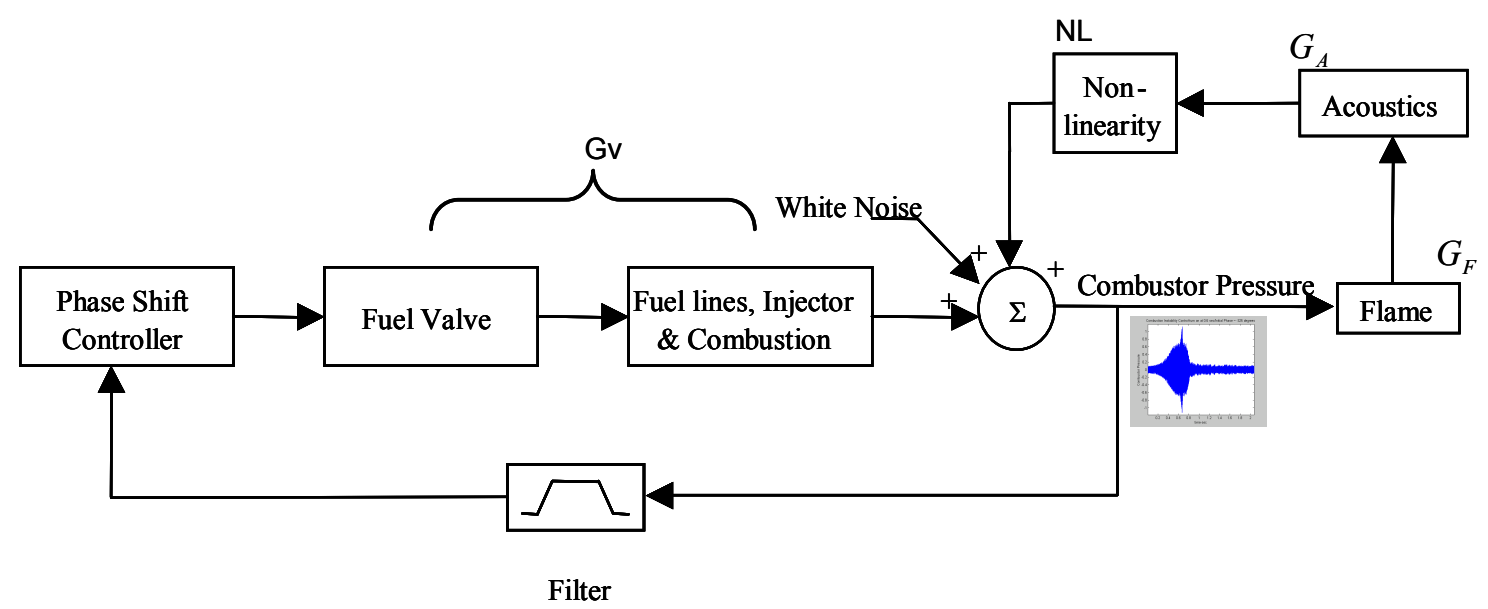

Figure 3 - Combustion Instability Control Block Diagram 


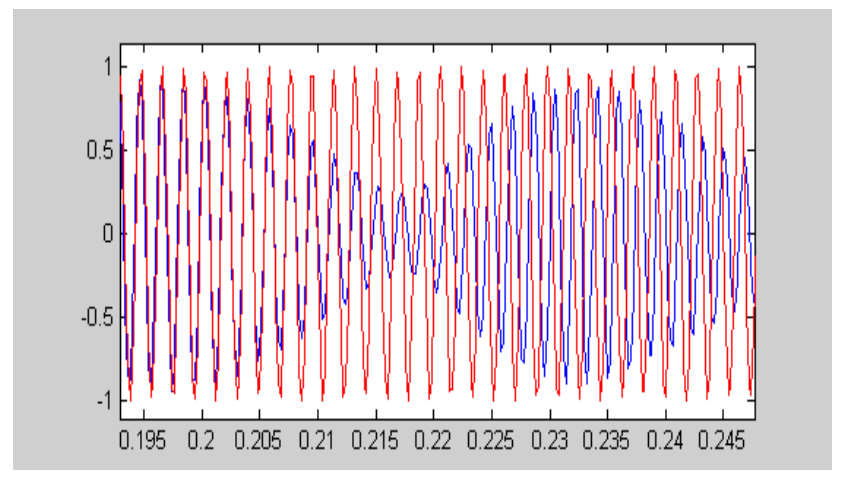

Figure 4 - Combustion Rig Filtered Instability Pressure (psi) versus Reference Sine Wave

not an undesirable feature with this simulation, as long as the results are repeatable (which they are). The saturation non-linearity and the combined model $\left(G_{V}\right)$ of the fuel valve dynamics, feed lines, injector, equivalence ratio modulation, and flame dynamics models are as follows:

$$
\begin{gathered}
N L=\tanh (p) \\
G_{V}=\frac{25.3 e 6}{s^{2}+6 e 3 s+25.3 e 6}
\end{gathered}
$$

where, $p$ is the acoustic pressure. The purpose of the $N L$ is to provide a soft limit for the instability. By soft limit the meaning here is that the amplitude of the instability will be limited when no forcing is applied, but also the amplitude can grow when forcing or fuel modulation is applied. Without $N L$, and due to the low damping and the numerical instability, the amplitude of the simulated combustor instability will grow unbounded. For the transfer function $G_{V}$, no modeling information was available, therefore, the assumption was that it had a second order, somewhat damped response and a passband that covered the instability frequency of $\sim 575 \mathrm{~Hz}$. Based on that, $G_{V}$ has the same damping and gain as for the LF configuration, only its frequency was changed.

The noise level was adjusted based on the averaged wideband noise of the rig in Figure 2, which produced averaged noise $\sim 7$ to 10 times higher than the instability. The open loop plant simulations produced similar results to those described in Reference 19 except that in this (HF) case, the time domain response is dominated by noise. This is due to the high noise-to-signal ratio of the HF rig configuration compared to the LF configuration.

As before, two identical band pass filters are placed in series in the feedback path. These filters achieve two objectives: 1) filtering out the process and sensor noise; and 2) representing the dead-time phase shift in the combustion process. Normally, the time delay associated with the delivery, injection, atomization, vaporization, and burning of the fuel would be included in the deadtime phase shift of the plant. However, for convenience, this dead-time phase shift has been included in the feedback path. Note: From block diagram this is not a standard feedback control system. The filter structure and attenuation characteristics for the HF case are the same as in Reference 19, only the band pass frequency was changed. Based on that, the state space model of the HF band pass filter used in the simulation, with a pass band frequency of 510 to $640 \mathrm{~Hz}$, is as follows:

$$
\begin{aligned}
& \dot{x}=A x+B u \\
& y=C x
\end{aligned}
$$

\begin{tabular}{|c|c|c|c|c|c|c|}
\hline \multicolumn{7}{|l|}{ With } \\
\hline \multirow{6}{*}{$A=1000$} & {$[-0.8$} & 0 & 0 & 3.58 & 0 & 0 \\
\hline & 0.8 & -0.8 & -0.8 & 0 & 3.58 & 0 \\
\hline & 0 & 0.8 & 0 & 0 & 0 & 3.58 \\
\hline & -3.58 & 0 & 0 & 0 & 0 & 0 \\
\hline & 0 & -3.58 & & 0 & 0 & 0 \\
\hline & 0 & 0 & -3.58 & 0 & 0 & 0 \\
\hline
\end{tabular}

$$
B=\left[\begin{array}{llllll}
800 & 0 & 0 & 0 & 0 & 0
\end{array}\right]^{T} \quad C=\left[\begin{array}{llllll}
0 & 0 & 1 & 0 & 0 & 0
\end{array}\right]
$$

This filter produces the same phase shift at the instability frequency as before. However, phase shift associated with dead time delay is expected to double with the HF rig configuration (assuming line lengths remain the same), because the frequency is approximately doubled. Therefore, with the HF configuration the total phase shift could be in the order of 1400 degrees.

Examining combustor rig experimental data shows the HF combustor instability exhibits net phase walks that can be as severe as 400 degrees per control cycle of $40 \mathrm{~Hz}$ (control cycle will be explained in the next section). In addition, this instability frequency is random, varying within approximately $+/-10 \mathrm{~Hz}$, centered at approximately $545 \mathrm{~Hz}$. Also, the instability continuously varies in amplitude. Figure 4 shows the rig instability pressure, filtered to remove the noise, against a reference sine wave of the same frequency and constant amplitude. This figure shows the instability undergoing amplitude modulations as well as random phase walk. With a more coherent instability, where the noise-to-signal ratio is low (like in the case of the LF rig configuration used previously or the actual engine-Figure 2), these adverse affects are less pronounced. Based on this, it is expected 
that suppressing a coherent instability with low noise-tosignal ratio would be a lot easier to accomplish. Analysis and testing to confirm this are being carried out and expected to be published at a later date.

The ASPAC was also evaluated briefly against a more physics-based model of the combustion rig. ${ }^{22}$ The physics based model was programmed in FORTRAN while the controller was in C language. It is expected that more evaluations of this type will be conducted in the future.

\section{CONTROL ALGORITHM}

Examining the control structure of Figure 3 a little more carefully gives a better understanding of one of the major challenges facing this control design. As the instability pressure is being suppressed via the controlled fuel modulation, the amplitude of the required fuel modulation continues to decrease. At some point the modulation amplitude becomes comparable to the amplitude of the noise. Therefore, as the instability is being suppressed, noise increasingly drives the process which ultimately will cause loss of control phase tracking (phase adaptation) resulting in the process becoming inherently unstable. Inherently unstable in this sense means that at some point as the instability is being suppressed, there will be no controlled phase modulation that will cause additional suppression. Rather, any modulation at this point, no matter what its amplitude and phase, will in fact cause amplification of the instability. Therefore, the desired operating command in this feedback control system, which calls for zero steadystate instability amplitude, is an inherently unstable point. In that sense, noise with this process becomes the limiting factor of how far down the instability can be suppressed. Of course, other process characteristics such as large phase delays are important too, but none are as important as noise in this control design.

Although the combustion process is rather complex, from a controls perspective, the desire is to simply find an opposing modulation phase that will suppress the instability. From this viewpoint, this behavior is equivalent to vector summation and vector rotation. The ASPAC algorithm senses the instability pressure, filters it, and averages the signal over a period of time (i.e. reduces the control bandwidth) in order to overcome the large process phase delay. It then phase shifts this signal to control the fuel valve in order to suppress the instability. The ASPAC controller consists of the following parts:

1. Continuous phase shift ( $10 \mathrm{kHz}$ sample time)

2. Adaptive control phase shift $(40 \mathrm{~Hz})$

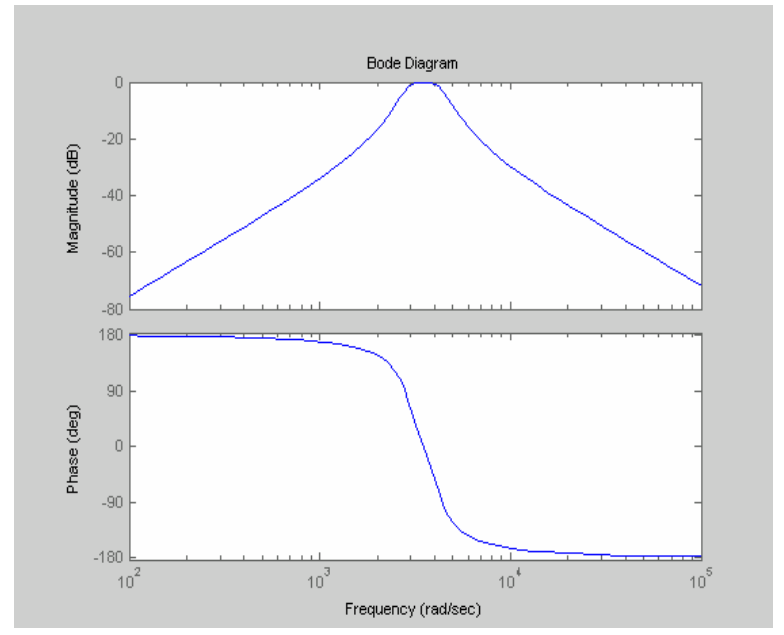

Figure 5 - Bode Plot of Band-Pass Filter

3. Discontinuous exponential gain modulation control $(\sim 500 \mathrm{~Hz})$

4. Adaptation of control parameters $(4 \mathrm{~Hz})$

\section{Continuous Phase Shift (part 1)}

In part 1, the instability is sampled at a rate of $10 \mathrm{kHz}$ and filtered to remove the noise. Then a phase shift angle (as computed in part 2) is applied, and this signal is output as a command to the fuel actuator, also at $10 \mathrm{kHz}$, to control the fuel modulation. When the controller is used to control the plant instead of the simulation, the design of the band pass filter is changed to reduce the phase shift. This is because the filter in the simulation (as discussed before), was also used to simulate the plant phase shift, which is no longer needed for the actual rig. The state space model of the band pass filter design for the actual HF plant controller, with a pass band of 450 to $700 \mathrm{~Hz}$ is:

$$
\begin{aligned}
& \dot{x}=A x+B u \\
& y=C x
\end{aligned}
$$

With

$$
\begin{gathered}
A=1000\left[\begin{array}{cccc}
-2.2627 & -1.6 & 3.51 & 0 \\
1.6 & 0 & 0 & 3.51 \\
-3.51 & 0 & 0 & 0 \\
0 & -3.51 & 0 & 0
\end{array}\right] \\
B=\left[\begin{array}{llll}
1600 & 0 & 0 & 0
\end{array}\right]^{T} \quad C=\left[\begin{array}{llll}
0 & 1 & 0 & 0
\end{array}\right]
\end{gathered}
$$

The Bode plot of the band pass filter is shown in Figure 5. When the controller was used against the simulation, the controller performed better as the width of the pass band was increased. However, as will be discussed in the 
controller testing section, the filter bandwidth had to be adjusted for the rig.

\section{Adaptive Control Phase Shift (part 2)}

This part of the control calculates the phase angle of the filtered instability signal (used in part 1), necessary to suppress the instability. Therefore, in part 2 the same filtered instability signal sensed at a $10 \mathrm{kHz}$ rate is averaged over a $40 \mathrm{~Hz}$ cycle in order to determine whether the amplitude of the instability signal is decreasing or increasing. If the instability amplitude is decreasing, the controller steps and advances the phase in the same direction as before. If the signal amplitude is increasing, the controller reverses the direction it is advancing the phase angle.

This part the algorithm, as shown in Figure 6, also computes a restricted control region. The control activity is restricted to operate within this region. The motivation for computing this restricted control region is to know in advance the phase region that promotes instability suppression. The reason for this is because intermediately in this control process, control phase tracking will be lost as suppression approaches the wideband noise level. A new restricted control region is computed whenever control suppression has been lost for a certain successive number of control cycles, and then suppression subsequently is recovered and continues for a predetermined number of control cycles.

Within the restricted control region the controller operates, sliding back and forth within a so-called effective stability region. The boundaries of this stability region are defined as the last phase angle in either direction that causes instability suppression. Once the controller phase stepping exceeds the phase angle at the boundary of this stability region, causing instability amplification, the controller reverses direction. This stable region continues to shrink as the instability is being suppressed further, until there exists no phase angle that will cause further suppression. This becomes the case because at this point the instability feedback signal is small enough that the noise now becomes the dominate driver in the process. When this inherently unstable point is reached the instability begins to amplify, and eventually the controller again succeeds in reestablishing control, thereby repeating the process over and over.

Discontinuous Exponential Gain Modulation Control (part 3)

This feature is active only when a restricted control region has been established (part 2). In this portion of the algorithm the controller proportional gain, by which the sensed instability is multiplied in part 1 , is modulated on and off. Even though, the on/off frequency is not fixed, the smallest duration of time for the gain "on" condition is equal to the pass-band filter low-pass corner frequency. The condition that triggers the gain "on" condition is decreasing instability amplitude over this time duration. The gain "off" condition is triggered by an increase in the instability signal amplitude. Instead, triggering the gain "on" when the instability amplitude is increasing and "off" otherwise, also worked well. This tends to indicate that generally discontinuous control modulation may be better than continuous. When the decision is made to turn the gain "on", a small time delay is applied first, and then the gain decays exponentially starting from an initial value. A simulation of the controller proportional gain is shown in Figure 7. This initial value of gain is also adapted in part 4 of the algorithm.

What motivates this Discontinuous Exponential Gain Modulation Control (DEGMC), is the very nature of a resonant mode coupled with noise - that is, when the

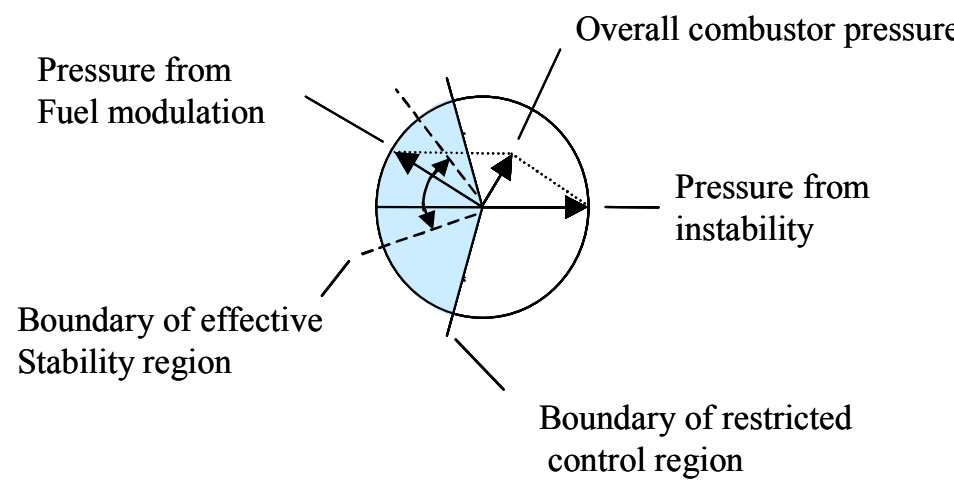

Figure 6 - ASPAC Phasor Diagram in a Stationary Frame of Reference 


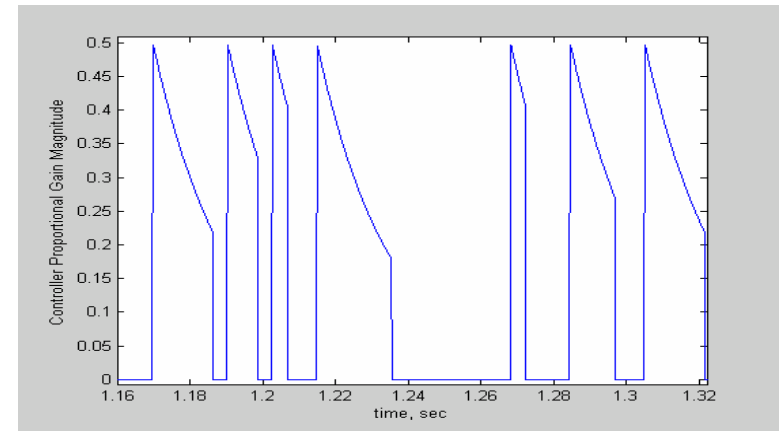

Figure 7 - Controller Proportional Gain Showing Discontinuous Exponential Gain Modulation

instability is sufficiently suppressed to the point that the process noise, Figure 3, provides a significant part of the excitation, additional suppression may become futile (reaching the point where the system becomes inherently unstable). The unintended result is amplification of the instability. Suppressing the instability only while its amplitude is decreasing seems feasible considering that resonant modes undergo amplitude modulation and any amplification will not be monotonically increasing on a cycle-by-cycle basis.

The motivation for the exponential gain decay is to overcome in a sense the large phase delay and its adverse effects that cause amplification of the effective control gain. The phase delay, which can be on the order of 1000 degrees for the HF configuration, can cause the effective control gain to vary by nearly an order of magnitude from its lowest to its highest value.

\section{Adaptation of Control Parameters (part 4)}

In part 4 , the control parameters are adapted sequentially and continuously at a rate of $4 \mathrm{~Hz}$ or less. The original controller design for the LF configuration discussed in Reference 19 did not include this control parameter adaptation. The control parameters which are adapted are the controller proportional gain, the exponential gain and the exponential gain delay discussed in part 3 , and the frequency of the adaptive phase shift discussed in part 2. In the case of the proportional control gain, this part of the control algorithm adapts the initial value of the gain used for exponential decay, (Figure 7). The adaptation methodology used in this case is called Adaptive Binary Search. ${ }^{23}$ This adaptation methodology essentially steps the control parameter adjustment in the direction that reduces the averaged instability signal amplitude, and reverses direction, halving the step size in the process when the amplitude of the signal increases.

\section{CONTROLLER TESTING}

The objective of the combustor rig testing was to assess the overall performance of the controller, in its ability to suppress the HF engine-like instability. Two separate tests were carried out using the ASPAC to control the HF configuration of the combustor rig described in section 1. The plan was to test each of the controller parts discussed in the previous section, and to tune the various controller parameters. However, due to facility problems during both tests, the test time was significantly limited. Also, some of the parameters were not successfully recorded, thus the controller did not get the chance to be exercised thoroughly in a methodical way. Despite these limitations, the data obtained successfully validated the control concept and demonstrated the ability of the controller to suppress the HF instability. The controller worked well even though the rig instability was not very coherent and there was considerable combustion noise.

The order of the controller testing was as follows: test the ability of the controller to suppress the instability and find the band pass filter that produces best performance, exercise the DEGMC portion of the algorithm, and finally exercise the parameter adaptation part.

Initial Instability Suppression and Filter Testing

At the beginning of rig testing a baseline case was run without feedback controls to establish the uncontrolled instability level. This baseline instability case was repeated after each series of controller testing. For the initial closed-loop control testing, only part 1 and part 2 of the ASPAC were run with band-pass filters of differ bandwidth. The filters tested in this portion of the

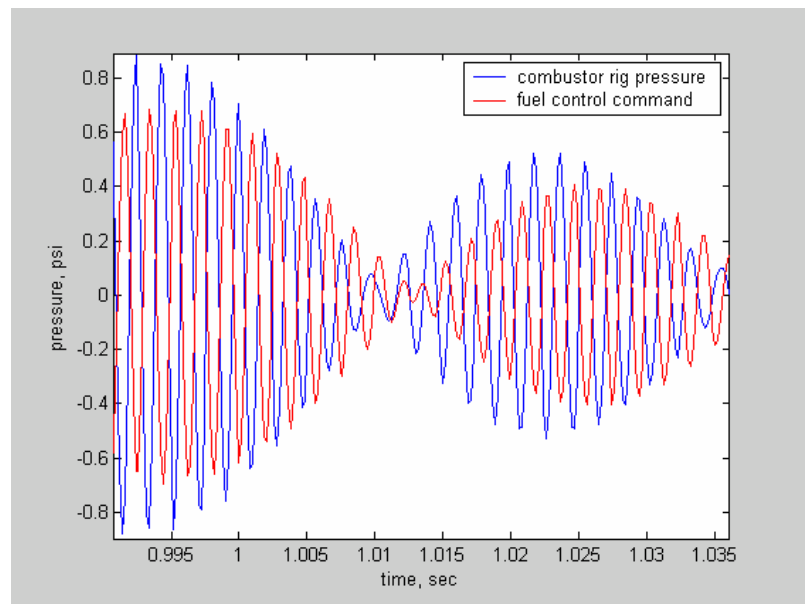

Figure 8 - Filtered Combustor Rig Pressure versus Filtered and Phase Shifted Fuel Valve Control Command 


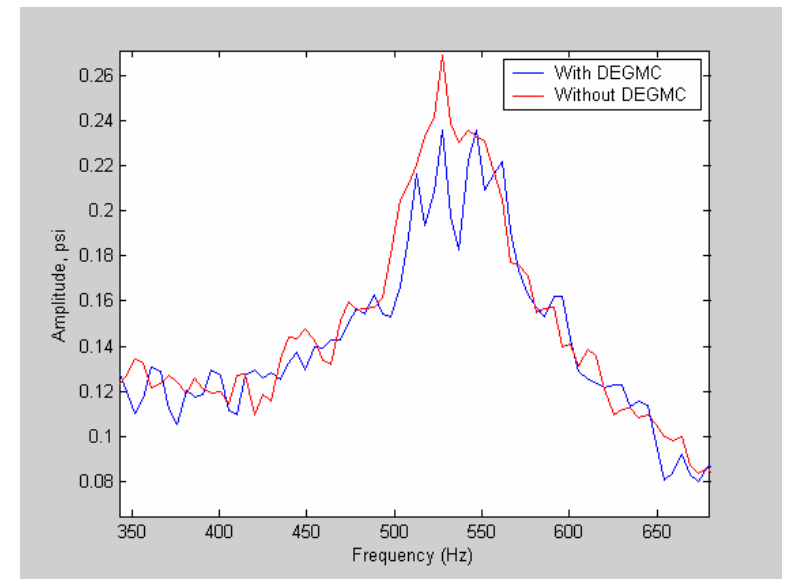

Figure 9 - Instability Suppression with and without Discontinuous Exponential Gain Modulation Control

controller evaluation had the following pass bands; no filter, 350 to 800,400 to 750,450 to 700,510 to 630 and 540 to $604 \mathrm{~Hz}$. The pass band of the last filter tested was slightly outside the instability center frequency (the instability frequency was not precisely known before the test). Through this part of testing, it was established that the band pass filter discussed in the previous section of 450 to $700 \mathrm{~Hz}$ pass band, achieved the best performance in suppressing the instability. The assumption is that with a relatively narrower band pass filter (narrower than 450 to $700 \mathrm{~Hz}$ ), the noise has a more pronounced effect since it's been concentrated near the instability frequency. On the other hand, too wide a pass band will not perform as well (as can be seen in Figure 2, the rig has high noise power at lower frequencies). There is also an added benefit with the fact that the wider pass band of 450 to $700 \mathrm{~Hz}$ is better for robustness: That is, this wider band is expected to cover the variability of the instability frequency for all operating conditions of a given engine configuration. Therefore, with the use of such a filter, there is no need to extract the instability frequency in real time. As seen in Figure 2, the shape of the actual engine spectral density differs from that of the rig, which means that the best filter design for the actual engine could be somewhat different from the simulation or the rig.

Figure 8 shows the combustor rig pressure and the controlled fuel modulation command. Both signals are filtered to show only the instability and the respective control command. Because the process has large phase delay, the control command has also been processed with a fixed phase shift. If the control signal is represented as $u_{c}=A \sin (\omega t+\theta)$, then the processed control signal is $u_{c, p r o c}=A \sin (\omega t+\theta+\phi)$, where $\varphi \cong \operatorname{Rem}\left(\phi_{p, \text { delay }} / 2 \pi\right)$ and $\phi_{p \text {,delay }}$ is the plant phase delay in radians. Rem stands for remainder. With this preprocessing, the combustor pressure and the control command shown in Figure 8 are displayed as if the plant has no phase transport delay, and the opposing phase of the controlled modulation to the combustor pressure is evident. This confirms that there is actual control of the instability taking place, as opposed to the controller causing some sort of excitation of the combustor pressure with the indirect affect of a net reduction in the instability pressure. This figure also shows that when the instability pressure is suppressed to nearly zero, the phase of the combustor pressure changes drastically, driven by the noise which dominates at this point. Even though the controlled signal phase starts opposing combustion pressure soon after the combustor pressure begins to grow again, the pressure still continues to grow for while. This sort of behavior supports earlier discussions that the plant becomes inherently unstable at suppression levels near the noise level. Second, the instability growth persists even though the controller is continuously opposing this action. This behavior seems to go beyond the effects of the large dead-time phase delay of the plant, and rather it points out that in addition, there exists instability inertia or some self-reinforcing mechanism. This later result is preliminary and will be further investigated in the future.

\section{Discontinuous Exponential Gain Modulation Control} Testing

DEGMC was exercised during control testing on the HF rig. Figure 9 shows instability suppression on the rig with and without DEGMC. The additional suppression due to DEGMC is $>10 \%$. However, when put into perspective of the noise effects, as will be discussed later in this section, the significance of this additional suppression will become clear. Since this new control design methodology (DEGMC) has not been fully evaluated, more performance assessments will need to be done.

After filter and DEGMC tuning, the amplitude spectra of the uncontrolled combustion instability against the controlled instability from the two separate tests are shown in Figure 10 and Figure 11. The amplitude suppression in the instability for test 1 and test 2 is approximately $30 \%$ and $40 \%$, respectively. The low frequency oscillation seen in the first test, Figure 10, is due to a separate valve mean flow controller. This was fixed in the second test.

From Figure 12, it can be seen that the combustion pressure is dominated by random noise. Because of the large amount of noise, the controller could only reduce the time domain RMS pressure by a few percent. But, 


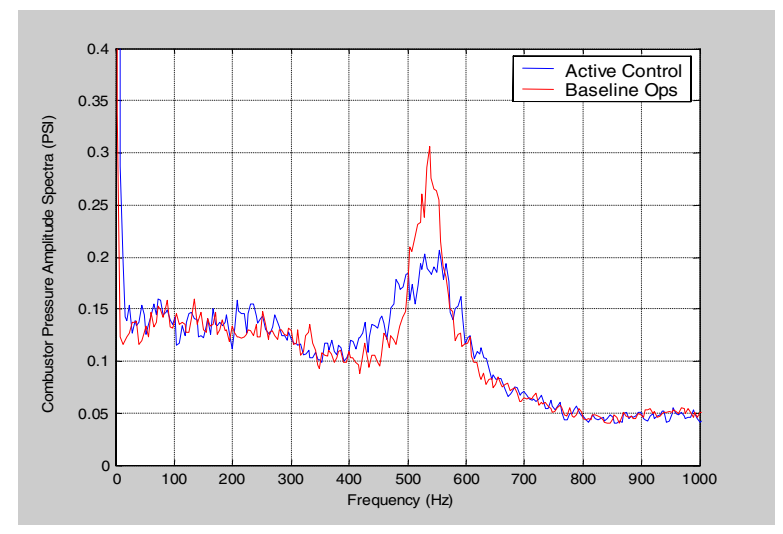

Figure 10 - Test 1, Amplitude Spectral Density of Uncontrolled versus controlled instability

even if complete elimination of the instability were possible, it would make only a few percent reduction in the amplitude of the time domain signal. Since the noise floor of the actual engine combustion pressure is significantly less than that exhibited by the rig, Figure 2, it is expected that in the case of the actual engine the controller will be able to more significantly reduce the peak time domain amplitudes and RMS value of the combustion pressure.

Since noise is the primary factor limiting the amount of instability suppression that is achievable, a new measure is proposed here for comparing the effectiveness of different controller designs in suppressing combustion instabilities. Instead of comparisons involving percentage or $\mathrm{dB}$ reduction compared to the uncontrolled instability amplitude, this preferred measure eliminates comparisons involving the uncontrolled instability. Rather, in terms of amplitude spectral density, the measure of success in suppressing combustion instability is based on how close to the noise floor the controller can suppress the instability. This new measure for comparing the effectiveness of various controller designs, defined below, is the Instability Suppression Ratio (ISR):

$$
I S R^{-1}=\frac{S_{N}}{S_{I}}
$$

Where $S_{N}$ is the average amplitude of the wide band noise spectra in the region of the instability, and $S_{I}$ is the peak amplitude spectra of the suppressed instability (provided that the controlled instability is discernibly less than the uncontrolled case). The interpretation of the average noise amplitude $S_{N}$, in cases where the wide band noise is not flat, would be the noise value at which the instability would be indistinguishable from the noise floor. Based on this definition, an ISR ${ }^{-1}$ of 1 would be the maximum possible suppression achievable, in which case the instability will be indistinguishable from the noise on

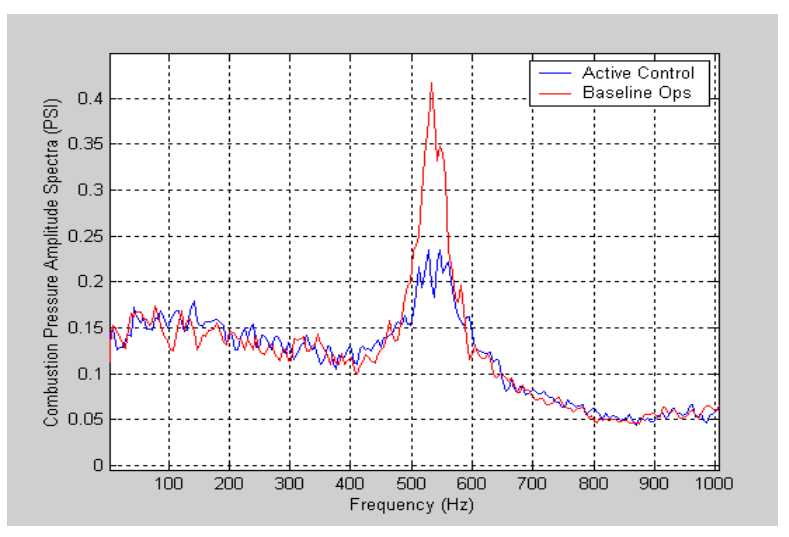

Figure 11 - Test 2, Amplitude Spectral Density of Uncontrolled versus controlled instability

a spectral density plot. Based on this measure, the values of $\mathrm{ISR}^{-1}$ achieved during the first and second test are approximately 0.70 and 0.60 , respectively. The fuel valve that was found to be partially clogged during the second test plus the limited test time could be reasons for the reduced performance of the controller during the second test. As discussed before and under this new measure of success, even $10 \%$ improvement in the $I_{S}{ }^{-1}$ is significant, especially when the ${\mathrm{I} S R^{-1}}^{-1}$ approaches 1 , making it increasingly more difficult to achieve additional suppression.

\section{Adaptation of Control Parameters Testing}

Control parameter adaptation was exercised during the second test. However, because of the limited time available and because there were problems with the data recording, an evaluation of this part of the control algorithm could not be conducted. Assuming that the instability signal is averaged for sufficiently long time, and that the adaptation steps are sufficiently large to avoid possible drifts of the optimized parameters, parameter adaptation is expected to work.

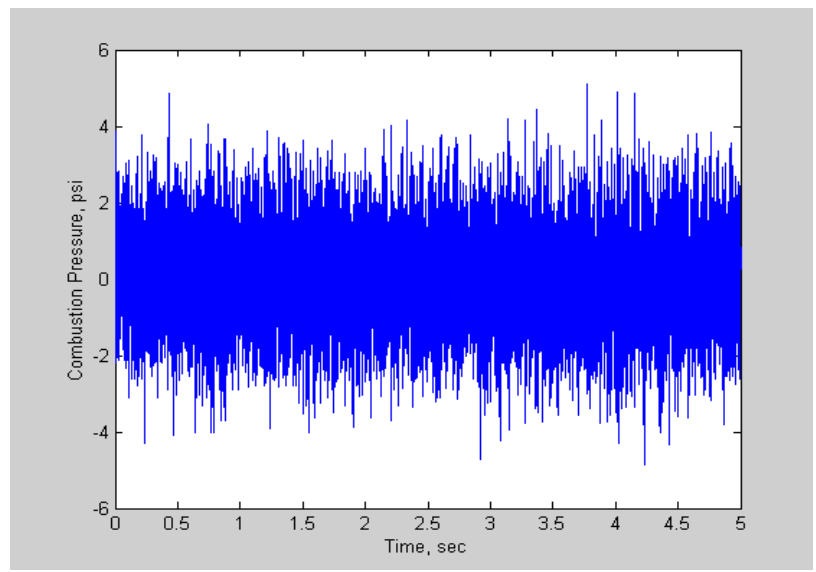

Figure 12 - Combustion Pressure of Controlled Instability 


\section{FUTURE PLANS}

Future plans include more testing with the HF rig configuration for a more thorough testing of the control algorithm. This high frequency testing will hopefully allow a more methodical tuning of the control parameters for better performance. Also, this testing will allow a more thorough evaluation of the parameter adaptation portion of the algorithm. Furthermore, frequency sweep tests will provide data to help derive a more accurate process model for future controls development.

Future plans also include testing the ASPAC algorithm against the extended, LF rig configuration. The LF configuration uses the same combustor with added length and volume in the diffuser section. The LF configuration exhibits a strong coherent instability at approximately $280 \mathrm{~Hz}$. This test will help evaluate the ability of the control algorithm to adapt to changing conditions, preferably without the need for major code modifications. This result has already been shown, at least partially, when the controller, developed against a LF simulation, was used without any essential code modification to control the $\mathrm{HF}$ combustor rig configuration. Also, since prior control developments have been done against the LF configuration, the LF test will allow a direct comparison with earlier control methods work. ${ }^{24}$

It is expected that future experimental work will be preceded by testing the ASPAC against the physics based model. $^{22}$ The objective is to use the physics based model for validation purposes before hardware testing.

Finally combustion instability test data for the LF and HF rig configurations as well as actual engine data are being analyzed to assess the characteristics of these different combustor configurations to gain a better understanding of instability behavior.

\section{CONCLUSION}

A combustion instability suppression control algorithm has been developed and successfully demonstrated on a combustor rig that incorporates many of the complexities of a real engine. The Adaptive Sliding Phasor Averaged Control (ASPAC) algorithm performs well with relatively high combustion noise, high dead-time phase shift, net random phase walk, some frequency randomness and amplitude modulation of the instability waveform. In addition, the algorithm responds relatively fast to suppress the instability and also to recover from loss of control tracking. This loss of tracking is unavoidable when the instability is sufficiently suppressed during control action. The control algorithm combines tracking control of the relative phase between instability pressure and fuel modulation with phase adaptation and control parameter adaptation. This combination is designed to allow good control of the instability even in cases when there are changes in the phase required for instability suppression such as those due to net random phase walks. Also, since this controller is not model based, its applicability is expected to be wide in terms of operating conditions and engine degradation, and even directly applicable to engines with different or variable geometries. Future work includes demonstration of this control approach on a different combustor rig configuration, integration of the control algorithm with a physics based model, and development of emission reduction controls combined with combustion instability controls.

\section{REFERENCES}

1. Lefebvre, A.H.: Gas Turbine Combustion, 2nd edition, Taylor and Francis, 1999.

2. McManus, K.R.; Poinsot, T.; and Candel, S.M.: "A Review of Active Control of Combustion Instabilities," in Progress in Energy and Combustion Science, Volume 19, Issue 1, P. 1-29, February 1993.

3. Dines, P.J.: “Active Control of Flame Noise," Ph.D. Thesis, Cambridge University, 1984.

4. Heckl, M.A.: "Active Control of Noise from a Rijke Tube," IUTAM Symposium on Aero and HydroAcoustics, Springer Verlag, pp. 211-216, 1985.

5. Sreenivasan, K.R.; Raghu, S.; and Chu, B.T.: "The Control of Pressure Oscillations in Combustion and Fluid Dynamical Systems, AIAA Shear Flow Conference, 1985.

6. Gleis, S.; Vortmeyer, D.; and Rau, W.: "Experimental Investigation of the Transition From Stable to Unstable Combustion by Means of Active Instability Control," Propulsion and Energetics Panel, 75th Symposium, AGARD, pp. 22:1-6, 1990.

7. Dowling, A.P.; Hooper, N.; Langhorne, P.J.; and Bloxsidge, G.J.: "Active Control of Reheat Buzz," AIAA 25th Aerospace Sciences Meeting, 1987.

8. Brouwer, J.; Ault, B.A.; Bobrow, J.E.; and Sumuelsen, G.S.: "Active Control for Gas Turbine Combustors," 23rd Symposium (International) on Combustion, The Combustion Institute, Pittsburgh, PA, 1990.

9. Allgood, D.; Campos-Delgado, D.U.; Acharya, S.; and Zhoo, K.: "Acoustic Control of Thermoacoustic Instabilities Using Experimental Model-Based Controllers," Proceedings of ASME Turbo Expo, New Orleans, LA, 2001. 
10. Cohen, J.M.; Rey, N.M.; Jacobson, C.A.; and Anderson, T.J.: "Active Control of Combustion Instability in a Liquid-Fueled Low-Nox Combustor," International Gas Turbine and Aeroengine Congress and Exhibition, Stockholm, Sweden, 1998.

11. Hibshman, J.R.; Cohen, J.M.; Banaszuk, A.; Anderson, T.J.; and Alholm, H.A.: "Active Control of Pressure Oscillations in a Liquid-Fueled Sector Combustor," International Gas Turbine and Aeroengine Congress \& Exhibition, Indianapolis, Indiana, 1999.

12. Johnson, C.E.; Neumeier, Y.; Nuemaier, M.; Zinn, B.T.: "Demonstration of Active Control of Combustion Instabilities on a Full-Scale Gas Turbine Combustor," Proceedings of ASME Turbo Expo, New Orleans, LA, 2001.

13. Murugappan, S.; Park, S.; Acharya, S.; Annaswamy, A.M.; Gutmark, E.J.; Ghoniem, A.F.: "Optimal Control of Swirl-Stabilized Combustor Using System Identification Based Model," Turbine Conference, Cesme, Turkey, 2000.

14. Murugappan, S.; Acharya, S.; Gutmark, E.J.; and Messina, T.: "Characteristics and Control of Combustion Instabilities in a Swirl-Stabilized Spray Combustor," 35th Joint Propulsion Conference and Exhibit, Los Angeles, CA, 1999.

15. Coker, A., Neumeier, Y., Lieuwen, T., Zinn, B.T., Menon, S.: "Studies of Active Instability Control Effectiveness in a High Pressure, Liquid Fueled Combustor," 41st Aerospace Sciences Meeting and Exhibit, Reno Nevada, 2003.

16. Lieuwen, C.; Zinn, B. T.: "Investigation of Cycle-toCycle Variability in an Unstable Gas Turbine Combustor," International Gas Turbine and Aeroengine Congress and Exhibition, Munich, Germany, 2000.

17. Le D.K.; DeLaat J.C.; Chang C.T.: "Control of Thermo-Acoustic Instabilities: The Multi-Scale Extended Kalman Approach," AIAA 39th Joint Propulsion Conference and Exhibit, Huntsville, AL, July 2003, AIAA-2003-4934.

18. DeLaat, J.C.; Chang, C.T.: “Active Control of High Frequency Combustion Instability in Aircraft GasTurbine Engines," to be presented at the 16th International Symposium on Air breathing Engines, Cleveland, Ohio, August 31-September 5, 2003.

19. Kopasakis, G.; DeLaat, J.C.: "Adaptive Instability Suppression Controls in a Liquid-Fueled Combustor," AIAA 38th Joint Propulsion Conference and Exhibit, Indianapolis, IN, July 2002, NASA/ TM-2002-211805, AIAA-2002-4075.
20. Cohen, J.M. et al: "Experimental Replication of an Aeroengine Combustion Instability," International Gas Turbine and Aeroengine Congress and Exhibition, Munich, Germany, 2000.

21. DeLaat, J.C.; Breisacher, K.J.; Saus, J.R.; Paxson, D.E.: "Active Combustion Control for Aircraft Gas Turbine Engines," 36th Joint Propulsion Conference and Exhibition, Huntsville, AL, 2000.

22. Paxson, D.E.: “A Sectored One-Demensional Model For Simulating Combustion Instabilities in Premix Combustors, AIAA 38th Aerospace Sciences Meeting and Exhibition, Rene, NV, January 2000. NASA/TM-1999-209771, AIAA-2000-0313.

23. Kopasakis, G.; Cairelli, J.E.; Traylor, R.M.: "Adaptive Vibrations Reduction Controls for a Cryocooler With a Passive Balancer," Cryogenic Engineering Conference, Madison, WI, July 2001, NASA/TM-2001-211094.

24. Barooah, P.; Anderson, T.J.; Cohen, J.M.: "Active Combustion Instability Control with Spinning Valve Actuator," Proceedings of ASME Turbo Expo, Amsterdam, Netherlands, June 2002. 


\begin{tabular}{|c|c|c|}
\hline \multicolumn{2}{|c|}{ REPORT DOCUMENTATION PAGE } & $\begin{array}{l}\text { Form Approved } \\
\text { OMB No. 0704-0188 }\end{array}$ \\
\hline \multicolumn{3}{|c|}{$\begin{array}{l}\text { Public reporting burden for this collection of information is estimated to average } 1 \text { hour per response, including the time for reviewing instructions, searching existing data sources } \\
\text { gathering and maintaining the data needed, and completing and reviewing the collection of information. Send comments regarding this burden estimate or any other aspect of thi } \\
\text { collection of information, including suggestions for reducing this burden, to Washington Headquarters Services, Directorate for Information Operations and Reports, } 1215 \text { Jefferson } \\
\text { Davis Highway, Suite 1204, Arlington, VA 22202-4302, and to the Office of Management and Budget, Paperwork Reduction Project (0704-0188), Washington, DC 20503. }\end{array}$} \\
\hline 1. AGENCY USE ONLY (Leave blank) & \begin{tabular}{|c|c|} 
2. REPORT DATE & 3. \\
July 2003 &
\end{tabular} & $\begin{array}{l}\text { D DATES COVERED } \\
\text { echnical Memorandum }\end{array}$ \\
\hline \multicolumn{2}{|c|}{$\begin{array}{l}\text { High Frequency Adaptive Instability Suppression Controls } \\
\text { in a Liquid-Fueled Combustor }\end{array}$} & 5. FUNDING NUMBERS \\
\hline $\begin{array}{l}\text { 6. AUTHOR(S) } \\
\text { George Kopasakis }\end{array}$ & & WBS-22-708-28-09 \\
\hline $\begin{array}{l}\text { 9. SPONSORING/MONITORING AGEI } \\
\text { National Aeronautics and Sp } \\
\text { Washington, DC 20546-00 }\end{array}$ & $\begin{array}{l}\text { NAME(S) AND ADDRESS(ES) } \\
\text { Administration }\end{array}$ & $\begin{array}{l}\text { 10. SPONSORING/MONITORING } \\
\text { AGENCY REPORT NUMBER } \\
\text { NASA TM-2003-212535 } \\
\text { AIAA-2003-4491 }\end{array}$ \\
\hline
\end{tabular}

Prepared for the 39th Joint Propulsion Conference and Exhibit cosponsored by AIAA, ASME, SAE, and ASEE, Huntsville, Alabama, July 20-23, 2003. Responsible person, George Kopasakis, organization code 5530, $216-433-5327$.

12a. DISTRIBUTION/AVAILABILITY STATEMENT

12b. DISTRIBUTION CODE

Unclassified - Unlimited

Subject Category: 01

Distribution: Nonstandard

Available electronically at http://gltrs.grc.nasa.gov

This publication is available from the NASA Center for AeroSpace Information, 301-621-0390.

13. ABSTRACT (Maximum 200 words)

This effort extends into high frequency $(>500 \mathrm{~Hz})$, an earlier developed adaptive control algorithm for the suppression of thermo-acoustic instabilities in a liquid-fueled combustor. The earlier work covered the development of a controls algorithm for the suppression of a low frequency $(\sim 280 \mathrm{~Hz})$ combustion instability based on simulations, with no hardware testing involved. The work described here includes changes to the simulation and controller design necessary to control the high frequency instability, augmentations to the control algorithm to improve its performance, and finally hardware testing and results with an experimental combustor rig developed for the high frequency case. The Adaptive Sliding Phasor Averaged Control (ASPAC) algorithm modulates the fuel flow in the combustor with a control phase that continuously slides back and forth within the phase region that reduces the amplitude of the instability. The results demonstrate the power of the method-that it can identify and suppress the instability even when the instability amplitude is buried in the noise of the combustor pressure. The successful testing of the ASPAC approach helped complete an important NASA milestone to demonstrate advanced technologies for low-emission combustors.

14. SUBJECT TERMS

Active combustion control

\begin{tabular}{|c|c|c|}
\hline $\begin{array}{c}\text { 17. SECURITY CLASSIFICATION } \\
\text { OF REPORT } \\
\text { Unclassified }\end{array}$ & $\begin{array}{c}\text { 18. SECURITY CLASSIFICATION } \\
\text { OF THIS PAGE } \\
\text { Unclassified }\end{array}$ & $\begin{array}{c}\text { 19. SECURITY CLASSIFICATION } \\
\text { OF ABSTRACT } \\
\text { Unclassified }\end{array}$ \\
\hline
\end{tabular}

NSN 7540-01-280-5500

Standard Form 298 (Rev. 2-89)

Prescribed by ANSI Std. Z39-18 298-102 